\title{
On the Ecological Reconstruction of the Coal Mining Area Based on the Sustainable Development
}

\author{
Caiping Meng \\ College of Surveying Science and Technology, Xi'an University of Science and Technology \\ 58 Yan Ta Road, ShaanXi, Xi'an, 710054, China \\ Tel: 86-29-8558-3176 E-mail: caiping_m@163.com
}

\begin{abstract}
The coal is the most important disposable energy in our country. Coal resources play a strategic role in our country's economic and social development, but there are a series of ecological environment problems about the mining and the utilization of coal resources. These problems in the coal mining area have already become an obstacle to the sustainable development and also a major hidden danger to the regional ecological security.

On the analysis of ubiquitous problems of the ecological environment in the coal mining area and supported by the theory of the sustainable ecological development, the thesis penetrates the characteristics and laws of the mine ecosystem succession and reconstructs the mine ecological industrial chain. To change the traditional thoughts of "development- pollution- governance", new ideas and ways of the sustainable development of the coal mining area have been put forward in order to achieve the harmonious development of economy, society and environment.
\end{abstract}

Keywords: Coal mining area, Ecological environment, Sustainable development, Ecosystem reconstruction

\section{Introduction}

In the long run, the coal is widely utilized in various national economic sectors as the important disposable energy in our country. Among all kinds of mineral areas, the coal mining area enjoys a top position in terms of its number, scale and distribution. Currently, there are over a hundred mineral cities in our country, about one fifth of the total number of cities. So the process of the sustainable development of the whole country relies largely on the sustainable growth of the coal mining area. But with the economic boom, a series of problems, such as exhausting coal resources, the contaminated ecological environment, frequent coal accidents, and so on, have become a serious obstacle to the sustainable development in coal mining area and a major hidden danger to the regional ecological security. The thesis inquires into the reconstructed strategies of coal mining area ecosystem on the basis of related ecological theories.

\section{Basic analysis of IECMA}

The coal mining area ecosystem is formed by the interactions of the human system, the natural environment system and the man-made economic system. It is an integrated ecosystem of coal mining area (IECMA) and is restricted by the laws of the natural eco-balance and the economy.

\subsection{Structure analysis of the IECMA}

IECMA is a changeable ecosystem. It can be divided into three interactive subsystems, i.e. the social, the economic and the natural subsystems, and each subsystem can be further divided into different systems, with each including various factors of its own. (See Fig.1)

\subsection{Characteristic analysis of the IECMA}

The structure of IECMA has been changed by the human, the circulations of material and energy been changed partly too. It is influenced by the human deeply, which is different from the natural ecosystem. IECMA has the following characteristics.

IECMA is a man-made ecological system deeply influenced by human activities. Due to the existence and production of human beings, the structure, the material circulation, and the energy transformation of the system have been changed completely or partially. Different from the natural ecosystem, IECMA has the following characteristics.

\subsubsection{The dominant position of human in IECMA}

For the sake of production and living, a large quantity of buildings and infrastructures for transportation and telecommunication are built. The main part of the coal mining area ecosystem has been changed into a man-made 
environment. Human occupies a dominant position in this ecosystem. The previous natural ecosystem has been destroyed seriously by human with the exploitation of coal resources. The IECMA becomes more complex and diversified due to the violent interference and high intensity of human activities.

\subsubsection{Fragility and incompleteness}

IECMA is an open, complex and gigantic system. It is different from the natural ecosystem due to its lack of the producer and the decomposer. On the one hand, the material and the energy have to be imported from outside; on the other hand, plenty of garbage must be disposed through proper methods that cause no harm to the environment. So IECMA is a very fragile, incomplete and unstable system.

\subsubsection{Complexity}

IECMA is a transitional belt for the interaction among atmosphere, the rocks, the organism and the soil. It is restricted by the regional geology and terrain conditions. At the same time it has close relations with the residents in the coal mining area. The system keeps on fluctuating due to the continuous mining. Once the balance of the IECMA is destroyed, it is hardly recovered within a short period of time.

\subsection{Stress analysis of the IECMA}

Coal mining leads to the pollution and the destruction of the ecological environment, which have caused serious threat for the economic and social development of the coal mining area. Through the analysis of the exterior stress, the effective regulation and solution can be taken.

\subsubsection{Pollution and destruction of water resources}

During the mining process, the water is drained off by the worker to ensure their securities. Meanwhile, the crackle that is formed by mining also leads to pollute water resources. The declining of grand water level causes the reduction of crops and collapse of the ground. The polluted water threatens the health of local residents.

\subsubsection{Occupation and pollution of land resources}

Plenty of garbage like the gangue discarded during the mining process often occupies large areas; furthermore, the harmful heavy metal in the garbage pollutes the land, the river and the atmosphere through the run off and the air dust, taking a worse effect on the environment.

\subsubsection{Destruction of ground vegetation}

Coal mining and the collapsed ground due to the mining destroys the landform and the green vegetation, accelerates the process of the water and soil erosion, reduces the land value and deteriorates the ecosystem.

\subsubsection{Pollution of atmosphere}

The coal buried underground contains a small amount of hydrocarbon gas, which is a kind of greenhouse gas given off through the mining tunnels. Besides, some other poisonous gases such as $\mathrm{H}_{2} \mathrm{~S} \& \mathrm{CO}$ etc are discharged via the tunnels. They pollute the atmosphere seriously.

\section{Reconstruction of IECMA}

Reconstruction of IECMA is to optimize and reorganize the structure, the component and the function under the support of manual work. Corresponding technical and economic measures are applied to solve the problems in the regressive succession of the ecosystem so as to reconstruct a sustainable ecosystem.

\subsection{Theoretical basis of reconstruction}

\subsubsection{Theory of ecological balance}

In nature, the ecosystem can regulate by itself. It can achieve a good condition where the components and the proportions hardly change, and the input and output of material and energy approximately equal. The condition is called ecological balance. But IECMA is an open and man-made ecosystem. In order to keep the ecosystem stable and ordered, the flows of material, energy and information must be regulated artificially so as to harmonize the system and establish a new balance.

\subsubsection{Law of ecosystem succession}

When the ecosystem experiences a series of fluctuations, a general trend comes into being that the organism variety becomes more than ever, the structure develops from simple to complex, the system from unstable to stable, and at the same time, the conditions of resources and environment are utilized abundantly. This evolution is called the progressive succession. On the contrary, the destroyed ecosystem goes backwards by the exterior stress. When the organism variety becomes less, the structure becomes single, the balance is lost and the environment is worsened. The condition is called regressive succession. This kind of phenomenon is common in the coal mining area. 


\subsection{Technical ways of reconstruction}

\subsubsection{Restoration of ecological environment}

Restoration of ecological environment is to reclaim the destroyed terrain and landform. It is feasible that the gangue and coal ash are used to reclaim the destructed land. The practice confirms that the reclaimed land improves a lot, the water and soil erosion declined and the soil fertility and the ecosystem enhanced. Good ecological and economic benefits are reaped.

\subsubsection{Optimization of system structure}

The principle of "adjusting measures to local conditions" should be implemented according with different characteristics of our country's geological environment. The reclaimed land in the middle and the west regions are suitable for establishing comprehensive agricultural developing region, so as to regulate the proportions of the agriculture, the forestry and the animal husbandry. However, the east regions are suitable for developing ecological agriculture and building new types of mining cities simultaneously. Through optimizing and arranging the structure model of ecosystem artificially, the self-regulation ability of the system can be enhanced and the proper operation of the system be realized.

\subsubsection{Construction of ecological industry chain}

The origin of the environment pollution and ecosystem destruction in the coal mining area lies in the unreasonable mining ways and low utilization rate of resources, especially the linear flow rather than the circular flow of material and energy. Too much disposed materials discharged in the form of wastes and detained in the environment block the recirculation route. The ecological industry chain must be established for the sake of enhancing the comprehensive utilization rate of coal and the reduction of discarded material, so as to achieve circulatory economy.

(1) Sanitizing production

Sanitizing production is to reduce the amounts of the discharged materials. At present, some sanitized production technologies are applied in the coal mining, such as innovation of tunnel layout for reducing the amount of rocks; filling the mining tunnel with the gangue; gas drawing and emitting technology; recycling the mining water, etc. Meanwhile, the technology of sanitized coal is implemented in full scale, the advanced technology of coal procession, utilization, transformation and burning are carried out, so as to reduce pollution to the full extent and to transform the coal into a kind of sanitary fuel.

\section{(2) Diversifying products}

Although great progress has been made on the utilization rate of coal in recent years, the average recyclable rate is only 40 percents, which is far below the average level of 80 percents in developed countries. The related data are shown in Table 1.To achieve the sustainable development, the coal products must be operated in a diversified way, from the single raw coal to varied kinds of coal products. As a result, the comprehensive utilization rate and the market competitive power can be enhanced.

\section{(3) Extending industry chain}

The coal resource is increasingly rare. In order to achieve the sustainable development, new technology and craft should be recommended to extend the industry chain, the coal-electricity, coal-building materials and coal-making gas-carbinol industry chains be built, and the extra value of the coal product increased greatly. At the same time, the industrial tourism should be developed vigorously to expand the industry chain.

\subsection{Management mechanism of reconstruction}

Environmental management in coal mining area is to manage the behaviors of enterprises. The purpose is to implement the green mining techniques, keep the balance of IECMA and avoid the exhaustion of coal resources and the degradation of environment. The coal mining environmental management mechanism should adopt the biological and engineering techniques and the economic, administrative and legal methods comprehensively. It is the basic way to achieve the reconstruction of IECMA.

\section{Conclusion}

Today, the situation of the resource and environment is very critical. We humankind have realized that we should get along with the nature harmoniously. The coal mining area is special for its environmental problems. The reconstruction measures must be carried out according to the characteristics.

On the whole, the reconstruction of IECMA aims to harmonize the relations among economic development and the environmental protection, the coal industry, the agriculture and the other industry. It is a long-term system engineering. The structure and the function of IECMA should be regulated by human on the basis of the theories of ecology and system engineering. Only putting the above listed biological and engineering measures into effect in coal mining area 
can we ensure the proper operation of IECMA and accomplish the sustainable developments of the economy, the social and the environment in the end.

\section{References}

Song, Zhimin. \& Cui, Shujun. (2000). Study on the Sustainable Development and Reconstruction of Ecological Environment in Coal Mining Area. Journal of Jiaozuo Institute of Technology, 19, 430-433.

Tu, Shihao. \& Chen, Yixian. (2003). Environment Protection in Mining Area Resulted From Green Mining. Energy Environmental Protection, 17, 10-13.

Wang, Guangcheng. \& Yan, Xuqian. (2006). Study on Theories and Methods of Ecosystem Health Assessment in Mining Area. Beijing: Economic Science Press, 41-51.

Wang, Yujun. \& Li, Tangjun. (1999). The Content and the Structure of Technique System of Sustainable Development in Coal Mining Area. World Coal Mining Report, 15, 12-16.

Wu, Lan. (2007).The Environmental Management of Coal Mining Area Based on the Sustainable Development. Inner Mongolia Science Technology \& Economy, 4, 60-61.

Yang, Xiaobo.\& Wu Qingshu. (2005). Ecological Science of the City. Beijing: Science Press, 50-52.

Table 1. Index of the coal comprehensive utilization rate from 2003 to 2007 in China

\begin{tabular}{|c|c|c|c|c|c|}
\hline Year & $\begin{array}{c}\text { Washing rate } \\
\text { of raw coal }\end{array}$ & $\begin{array}{c}\text { Utilization rate } \\
\text { of mine water }\end{array}$ & $\begin{array}{c}\text { Utilization rate } \\
\text { of solid garbage }\end{array}$ & $\begin{array}{c}\text { Utilization rate } \\
\text { of the drawn gas }\end{array}$ & $\begin{array}{c}\text { Average } \\
\text { recyclable rate }\end{array}$ \\
\hline 2003 & $20 \%$ & $30 \%$ & $30 \%$ & $20 \%$ & $10-15 \%$ \\
\hline 2005 & $32 \%$ & $44 \%$ & $43 \%$ & $40 \%$ & $20-30 \%$ \\
\hline 2007 & $50 \%$ & $70 \%$ & $70 \%$ & $60 \%$ & $40 \%$ \\
\hline
\end{tabular}

Note: Data from the document of $<$ Opinion on the work of saving energy and reducing emission of the coal industry>issued by the National Development and Reform Commission and the State Environmental Protection Administration in 2007.

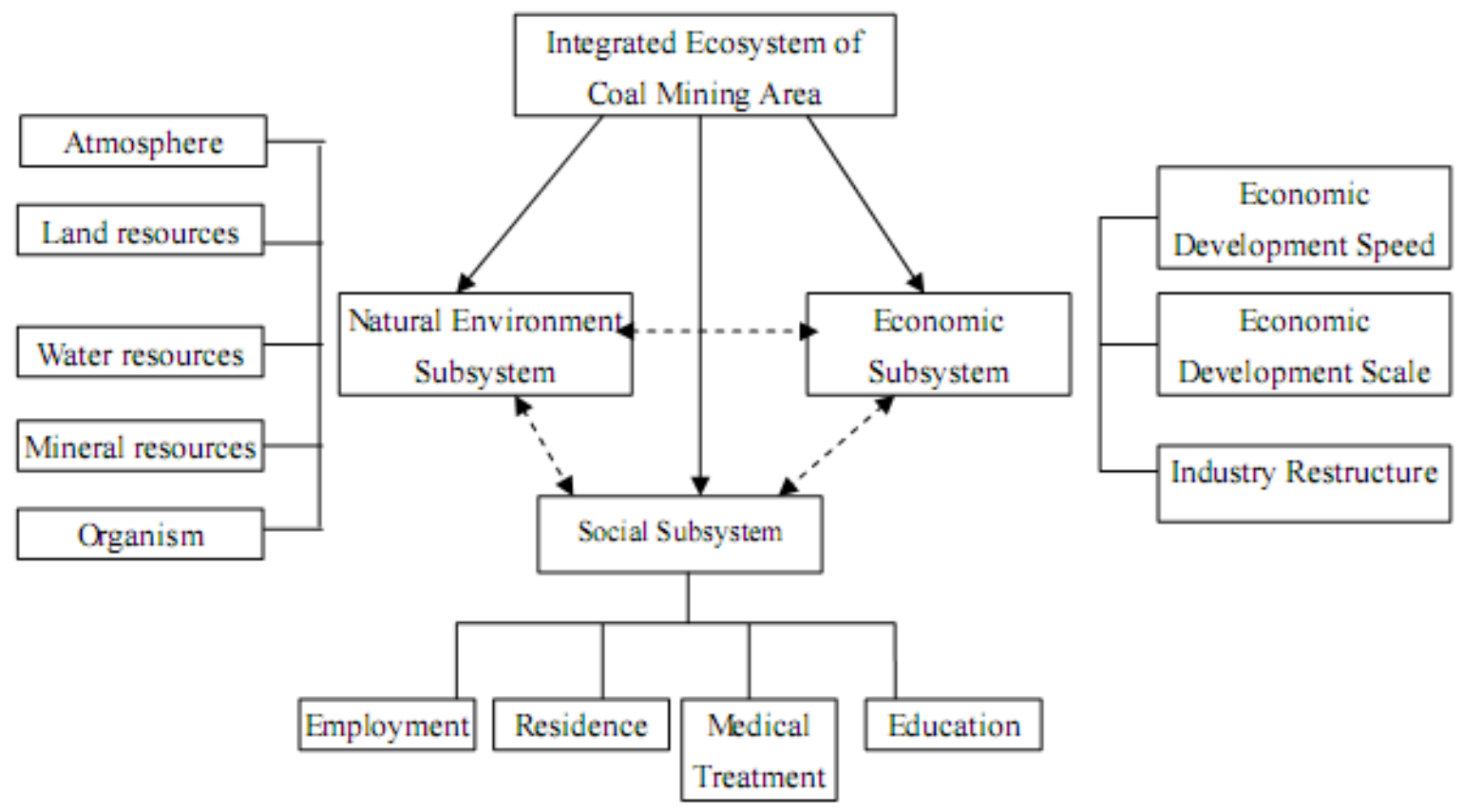

Figure 1. The Structure of Integrated Ecosystem of Coal Mining Area 